\title{
Haplotypes of Polymorphic Antigen Processing Genes for Low Molecular Mass Polypeptides (LMP2 and LMP7) are Strongly Associated with Type 1 Diabetes in North India
}

\author{
Bhukya Saida, Prachi Dani, Nachiketa Patnaik, Bharti Agrawal, T Rajarathna, Anushree Jaiswal, Alok Kumar Singh and Rajni Rani*
}

Molecular Immunogenetics Group, National Institute of Immunology, Aruna Asaf Ali Marg, New Delhi-110067, India

\begin{abstract}
Objective: Type 1 diabetes (T1D) is a multifactorial autoimmune disorder where several genes have been implicated. Aberrant presentation of auto-antigens on the MHC molecules is the hallmark of autoimmune disorders. The antigen is processed into small peptides by low molecular mass polypeptides, LMP2 and LMP7 before they are presented on the MHC class-I molecules. We have studied the associations of the Single nucleotide polymorphisms (SNPs) in these antigen processing genes and their haplotypes which may be detrimental for the processing of the
\end{abstract} auto-antigens in T1D.

Methods: 239 T1D subjects and 752 normal healthy controls from North India were studied for $L M P 2$ codon $60 \mathrm{G} / \mathrm{A}(\mathrm{R} / \mathrm{H}), \mathrm{LMP} 7$ codon 49 of $\mathrm{C} / \mathrm{A}(\mathrm{Q} / \mathrm{K})$ and $L M P 7$ Intron $6 \mathrm{G} / T$ polymorphisms using PCR-RFLP. HLA class-II alleles were studied using bead based Luminex assays. Haplotypes of $L M P 2$ and $L M P 7$ were constructed using SHEsis online software. $X^{2}$ test was used to study the significance of differences between patients and controls.

Results: The $G(R)$ allele $(p<0.009)$ and homozygous $G G(R R)$ genotype $(p<0.01)$ of $L M P 2$ codon $60, C(Q)$ allele $(p<0.0098)$ and homozygous CC (QQ) $(p<0.03)$ of $L M P 7$ codon 49 and $L M P 7$ Intron $6 \mathrm{G}$ allele $(p<0.01)$ were significantly increased in T1D subjects compared to controls. Haplotype analysis showed that haplotypes $G C G$ and ACT (LMP2 codon 60- LMP7codon 49- LMP7 intron 6) $\left(p<5.9 \times 10^{-13}, p<1.9 \times 10^{-8}\right.$ respectively) were significantly increased and haplotypes GCT and ACG $\left(p<1.9 \times 10^{-12}, p<1.9 \times 10^{-13}\right.$ respectively) were significantly reduced in T1D patients irrespective of the gender, age at onset of T1D and the predisposing HLA DRB1*03:01.

Conclusion: Association of $L M P 2$ and $L M P 7$ haplotypes GCG and ACT with T1D may have a role in processing of auto-antigens to be presented by MHC class-I molecules to cytotoxic T cells in T1D.

\section{Introduction}

Type 1 diabetes (T1D) is an incurable, multifactorial and complex autoimmune disorder. In T1D, most of the insulin producing beta cells of the pancreas are lost before the disease manifests itself in the form of abnormal glucose metabolism. Uncontrolled hyperglycemia may result in complications like ketoacidosis, retinopathy, nephropathy and even cardio-vascular diseases and pre-mature death [1].

World-wide disease affects 1 in 300-400 children [2]. The prevalence in India is $10.20 / 100,000$ with higher prevalence of $26.6 / 100,000$ in urban areas compared to $4.27 / 100,000$ in rural areas [3]. While several genetic [4-6] and environmental factors have been implicated in autoimmune destruction of the insulin producing Pancreatic Beta cells, the association of the Major Histocompatibility complex (MHC) class-II alleles has been shown to be the strongest [5-7]. The function of the MHC molecule is to present antigenic peptides to the T cells for the immune response to take place. However, for the peptides to be presented on the MHC molecule, the antigenic proteins need to be processed into small peptides and loaded on to the peptide binding groove of the MHC molecule. Cytosolic or viral proteins are processed in the cytoplasm by a complex of proteosomes, which include interferon-gamma (IFN- $\gamma$ ) inducible low molecular mass proteases or polypeptide complex 2 and 7 (LMP2 and LMP7), also known as proteasome subunit beta type-9 (PSMB9) and Proteasome subunit beta type-8 (PSMB8) respectively [8-12].

LMP2 and LMP7 seem to have peptide editing function since they select the peptides to be presented on MHC class-I molecules and thus modulate the immune response against self or non-self antigens. Proteosomes have also been shown to mediate the processing and activation of the transcription factor, nuclear factor- $\mathrm{kB}(\mathrm{NF}-\mathrm{\kappa B})$ [13], which regulates the expression of other downstream genes involved in immune responses like cytokine and chemokine genes [13].

Because of their functional implications in terms of antigen presentation and immune responses, we studied single nucleotide polymorphisms (SNPs) in LMP2 and LMP7 genes to determine their association with Type 1 diabetes, age at onset and gender bias in a North Indian population.

\section{Materials and Methods}

\section{Patients and control populations}

Two hundred and thirty nine T1D subjects (105 females, mean age at onset $14.74 \pm 7.57$ and 134 males, mean age of onset $16.89 \pm 7.25$ ) recruited from 'Type 1 Diabetes Clinic' at All India Institute of Medical Sciences, New Delhi, India, in a consecutive manner from 2004-2008,

*Corresponding author: Rajni Rani, Molecular Immunogenetics Group, National Institute of Immunology, Aruna Asaf Ali Marg, New Delhi-110067, India, Tel: 91-11 26703545; Fax: 9111-26742125; E-mail: rajni@nii.ac.in

Received July 18, 2014; Accepted October 09, 2014; Published October 11 2014

Citation: Saida B, Dani P, Patnaik N, Agrawal B, Rajarathna T, et al. (2014) Haplotypes of Polymorphic Antigen Processing Genes for Low Molecular Mass Polypeptides (LMP2 and LMP7) are Strongly Associated with Type 1 Diabetes in North India. J Diabetes Metab 5: 451 doi:10.4172/2155-6156.1000451

Copyright: $\odot 2014$ Saida B, et al. This is an open-access article distributed unde the terms of the Creative Commons Attribution License, which permits unrestricted use, distribution, and reproduction in any medium, provided the original author and source are credited. 
Citation: Saida B, Dani P, Patnaik N, Agrawal B, Rajarathna T, et al. (2014) Haplotypes of Polymorphic Antigen Processing Genes for Low Molecular Mass Polypeptides (LMP2 and LMP7) are Strongly Associated with Type 1 Diabetes in North India. J Diabetes Metab 5: 451 doi:10.4172/21556156.1000451

Page 2 of 9

that were part of our earlier studies $[5,14]$ and 752 normal healthy controls (199 females and 553 males, mean age of $31.86 \pm 20.03$ ) from the same ethnic background were studied for LMP2 and LMP7 SNPs after obtaining informed written consent and Institutional Human Ethics Committee's approval from both All India Institute of medical Sciences and National Institute of Immunology, New Delhi. All subjects i.e. patients and controls were based in Delhi, originally from three states of North India, Uttar Pradesh, Haryana and Punjab. The controls were the random healthy individuals with no disease, symptoms of a disease or family history of any autoimmune or infectious disease and comprised of students, scholars and employees of NII and AIIMS, who gave informed consent.

\section{PCR amplification and genotyping:}

Third exon of LMP2 and second exon and sixth Intron of $L M P 7$ were amplified using Polymerase Chain Reaction (PCR) using standard conditions and primers described by Casp et al. [11] listed in Table 1. SNP genotypes were determined by restriction fragment length polymorphism (RFLP) analysis of the PCR products as described [11] The digested fragments were resolved on $3 \%$ agarose gel electrophoresis in TBE buffer. The single SNP studied from $L M P 2$ was $G / A$ substitution at codon 60 in exon 3, studied using restriction endonuclease Hha I, which cleaves the $\mathrm{G}$ allele, but not the A allele (Figure 1a). LMP7 exon 2 SNP $A / C$ at codon 49 was studied using restriction enzyme Pst-I which cleaves the $C$ allele and the $A$ allele remains uncut (Figure 1b). LMP7intron $6 \mathrm{SNP}$ was studied using Hha I enzyme which cleaves the $G$ allele but not the $T$ allele (Figure 1c). Figure 1 shows the interpretations of different genotypes based on PCR-RFLP patterns.

\section{HLA-DRB1 polymorphism}

Alleles of HLA-DRB1 locus were studied for 199 T1D patients and 350 controls for whom $L M P 2$ and $L M P 7$ data were available as described earlier using either ${ }^{32} \mathrm{P}$ - labeled sequence specific oligonucleotide probes (SSOP) or Luminex based HLA typing using Labtype SSO kit from One Lambda, (Canoga Park, CA, USA) according to the manufacturer's instructions as described earlier $[5,15]$.

\section{Statistical analysis}

The significance of differences in allelic and genotypic frequencies between T1D patients and controls was determined by standard $\chi^{2}$ tests, Odds ratios and 95\% confidence intervals using Stata 9.2 software. However, whenever the numbers in any group (i.e. in cases

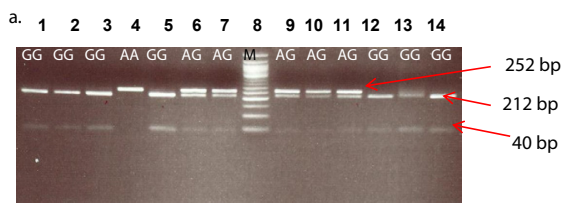

\begin{tabular}{llll} 
d. & & & \\
\hline Gene & $\begin{array}{l}\text { Single nucleotide } \\
\text { Polymorphism }\end{array}$ & $\begin{array}{l}\text { Restriction } \\
\text { enzyme }\end{array}$ & Fragment sizes \\
\hline $\begin{array}{l}\text { LMP2 } \\
(P S M B 9)\end{array}$ & $\begin{array}{l}\text { CGC/CAAC } \\
\text { Exon 3 }\end{array}$ & Hhal & $\begin{array}{l}G: 212,40 \mathrm{bp} \\
A: 252 \mathrm{bp}\end{array}$ \\
& & & \\
$\begin{array}{l}\text { LMP7 } \\
(P S M B 8)\end{array}$ & CXAG/AAG & Pst1 & $\begin{array}{l}\text { C: } 194,18 \mathrm{bp} \\
A: 212 \mathrm{bp}\end{array}$ \\
& & & \\
$\begin{array}{l}\text { EMP7 } \\
(P S M B 8)\end{array}$ & G/T intron 6 & Hhal & $\begin{array}{l}G: 428,180,155 \mathrm{bp} \\
T: 583,180 \mathrm{bp}\end{array}$
\end{tabular}

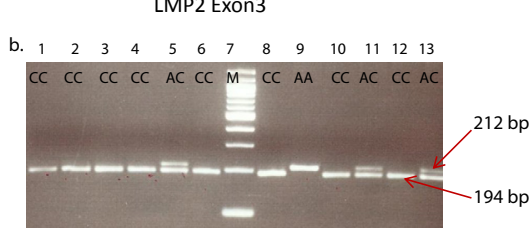

(PSMB8) $T: 583,180$ bp

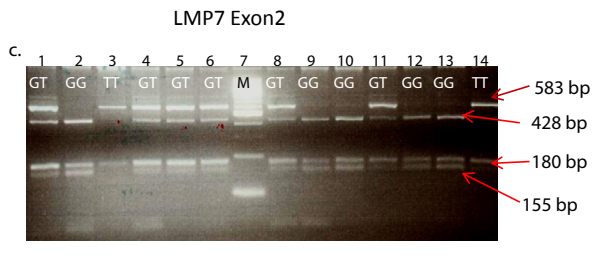

LMP7 Intron 6

Figure 1: Representative pictures of gels showing restriction digestion pattern and genotyping for single nucleotide polymorphisms (SNPs) in a. LMP2 exon 3 (G/A) lanes 1-3, 5, 12-14: GG homozygous, lane 4 :AA homozygous and lanes 6,7,9-11: AG heterozygous \& lane $8 \mathrm{M}: 50 \mathrm{bp}$ marker, b. LMP2 Exon2 (C/A) lanes 1-4, 6, 8 10 and 12: CC homozygous, lanes 511 and $13:$ AC heterozygous, lane $9:$ AA homozygous and lane 7 M: 100 bp marker, c. LMP7 Intron 6 G/T) lanes 1, 4-6, 8 and 11 GT heterozygous, lanes 2,9,10,12,13: GG homozygous and lanes 3 and 14 TT homozygous, lane $7 \mathrm{M}$ : 100 bp marker, d. Table showing the SNPs on three loci, restriction enzymes used and the fragment sizes obtained after restriction digestion to decipher the SNPs.

\begin{tabular}{|c|c|c|c|c|c|}
\hline \multirow{2}{*}{ Gene } & \multirow{2}{*}{ Single nucleotide Polymorphism } & \multicolumn{2}{|r|}{ PCR primers } & \multirow{2}{*}{ Restriction enzyme } & \multirow{2}{*}{ Fragment sizes } \\
\hline & & Name & Sequences ( $5^{\prime}$ to $\left.3^{\prime}\right)$ & & \\
\hline \multirow[t]{2}{*}{ LMP2 (PSMB9) } & CG $\mathrm{G} / \mathrm{CAC}$ codon $60(\mathrm{R} 60 \mathrm{H})[11,42]$ & LMP2-2 & GTGAACCGAGTGTTTGACAAGC & Hha1 & $G: 212,40 \mathrm{bp}$ \\
\hline & rs 17587 & LMP2-1 & GCCAGCAAGAGCCGAAACAAG & $37^{\circ} \mathrm{C}$ for 4 hours & A: 252 bp \\
\hline \multirow[t]{2}{*}{ LMP7 (PSMB8) } & $\underline{\mathrm{C}} \mathrm{AG} / \underline{\mathrm{A} A G}$ codon $49(\mathrm{Q} 49 \mathrm{~K})[11,42]$ & LMP7-Z & TCGCTTTACCCCGGGGAㄷTG ${ }^{a}$ & Pst1 & $C: 194,18 \mathrm{bp}$ \\
\hline & rs2071543 & LMP7-BR & AАCTTGCACTTCCTCCTCTCAGG & $37^{\circ} \mathrm{C}$ for 2 hours & $A: 212 \mathrm{bp}$ \\
\hline \multirow[t]{2}{*}{ LMP7 (PSMB8) } & $\mathrm{G} / \mathrm{T}$ intron $6[11,25]$ & LMP7-7 & TTGATTGGCTTCCCGGTACTG & Hha1 & G: $428,180,155 b p$ \\
\hline & & LMP7-4 & TCTACTACGTGGATGAACATGG & $37^{\circ} \mathrm{C}$ for 5 hours & $T: 583,180 \mathrm{bp}$ \\
\hline
\end{tabular}

Table 1: Primers used for amplification of $L M P 2$ exon 3, LMP 7 Exon 2 and Intron 6 for SNP genotyping [11]. 
Citation: Saida B, Dani P, Patnaik N, Agrawal B, Rajarathna T, et al. (2014) Haplotypes of Polymorphic Antigen Processing Genes for Low Molecular Mass Polypeptides (LMP2 and LMP7) are Strongly Associated with Type 1 Diabetes in North India. J Diabetes Metab 5: 451 doi:10.4172/21556156.1000451

Page 3 of 9

or controls) were less than 5 for any allele Fisher's exact test was used. In such cases, Odds ratios were calculated using Woolf's method [16] with Haldane's [17] modification as described earlier [18]. $p$ values were corrected using Bonferroni's correction for multiple comparisons. Linkage disequilibrium between HLA alleles and LMP haplotypes were calculated as described earlier [5]. Haplotype analysis for LMP2-LMP7 SNPs, haplotype association with disease, gender and age at onset were done using online SHEsis software [19,20] (http://202.120.31.177/ myAnalysis.php).

\section{Results}

\section{Genotype, allele and haplotype frequencies of LMP2 and LMP7 SNPs in T1D patients as compared to controls}

Genotype, allele and haplotype frequencies of $L M P 2$ exon $3 \mathrm{G} / \mathrm{A}$, $L M P 7$ exon $2 A / C$ and $L M P 7$ intron $6 \mathrm{G} / \mathrm{T}$ are shown in Table 2. All genotype frequencies in patients as well as controls were in Hardy Weinberg equilibrium. The $G$ to $A$ substitution in $L M P 2$ exon 3 leads to an amino acid change from arginine $(\mathrm{R})$ to histidine $(\mathrm{H})$ at codon 60 (CGC to $C A C)$. A significant increase in the frequency of $\mathrm{G}(\mathrm{R})$ allele $(\mathrm{p}<0.009)$ and homozygous $G G(\mathrm{RR})$ genotype $(\mathrm{p}<0.01)$ was observed in T1D patients compared to healthy controls. These differences were significant even after Bonferroni's correction.

In $L M P 7$ exon 2 substitution of $C$ to $A$ results in amino acid change from glutamine (Q) to Lysine (K) at codon 49 (CAG/AAG). Allele $C$

\begin{tabular}{|c|c|c|c|c|c|c|c|}
\hline \multirow{2}{*}{$\begin{array}{l}\text { Genotype/ } \\
\text { allele }\end{array}$} & \multicolumn{2}{|c|}{ TID } & \multicolumn{2}{|c|}{ Controls } & \multicolumn{3}{|c|}{ T1D Vs Controls } \\
\hline & $\begin{array}{c}\mathrm{N}=228 \\
\text { No. }\end{array}$ & $\%$ & $\begin{array}{c}\mathrm{N}=752 \\
\text { No. }\end{array}$ & $\%$ & p Value & $\begin{array}{l}\text { Odds } \\
\text { ratio }\end{array}$ & (95\% C.I.) \\
\hline GG (RR) & 166 & 72.8 & 480 & 63.82 & 0.012 & 1.52 & $1.08-2.14$ \\
\hline$A G(H R)$ & 57 & 25.00 & 241 & 32.05 & 0.04 & 0.71 & $0.49-0.99$ \\
\hline$A A(H H)$ & 5 & 2.19 & 31 & 4.12 & $0.17^{*}$ & $0.56^{* *}$ & $0.29-1.1$ \\
\hline$G(R)$ & 389 & 85.3 & 1201 & 79.85 & 0.009 & 1.46 & $1.09-1.98$ \\
\hline$A(H)$ & 67 & 14.7 & 303 & 20.14 & 0.009 & 0.68 & $0.5-0.92$ \\
\hline LMP7 exon 2 & $\mathrm{~N}=\mathbf{2 2 5}$ & $\%$ & $N=742$ & $\%$ & & & \\
\hline$C C(Q Q)$ & 173 & 76.88 & 516 & 69.54 & 0.03 & 1.45 & $1.02-2.1$ \\
\hline$A C(K Q)$ & 48 & 21.33 & 191 & 25.74 & 0.18 & 0.78 & $0.53-1.13$ \\
\hline$A A(K K)$ & 4 & 1.77 & 35 & 4.72 & 0.03 & 0.4 & $0.2-0.81$ \\
\hline$C(Q)$ & 394 & 87.55 & 1223 & 82.41 & 0.0098 & 1.5 & $1.1-2.1$ \\
\hline$A(K)$ & 56 & 12.45 & 261 & 17.58 & 0.0098 & 0.66 & $0.47-0.91$ \\
\hline LMP7 Intron 6 & $\mathrm{~N}=\mathbf{2 3 0}$ & $\%$ & $N=738$ & $\%$ & & & \\
\hline GG & 90 & 39.13 & 245 & 33.2 & 0.09 & 1.29 & $0.94-1.77$ \\
\hline$G T$ & 106 & 46.08 & 332 & 44.99 & 0.77 & 1.04 & $0.77-1.4$ \\
\hline$T T$ & 35 & 14.78 & 161 & 21.81 & 0.03 & 0.64 & $0.42-0.97$ \\
\hline$G$ & 286 & 62.17 & 822 & 55.7 & 0.01 & 1.3 & $1.05-1.63$ \\
\hline$T$ & 174 & 37.83 & 654 & 44.3 & 0.01 & 0.76 & $0.61-0.95$ \\
\hline
\end{tabular}

Haplotypes LMP2 exon 3, LMP7 exon 2, LMP7 intron 6@s

\begin{tabular}{|l|c|c|c|c|c|c|c|}
\hline & $\mathbf{2 N = 4 1 2}$ & $\mathbf{9}$ & $\mathbf{2 N = 1 4 7 6}$ & $\mathbf{\%}$ & & & \\
\hline $\mathbf{G C G}$ & 257 & 62.37 & 584 & 39.56 & $5.9 \times 10^{-13 *}$ & 2.29 & $1.83-2.88$ \\
\hline $\boldsymbol{A C T}$ & 58 & 14.1 & 80 & 5.42 & $1.9 \times 10^{-8 *}$ & 2.7 & $1.89-3.87$ \\
\hline $\mathbf{G C T}$ & 46 & 11.16 & 387 & 26.22 & $1.9 \times 10^{-12 *}$ & 0.32 & $0.23-0.44$ \\
\hline ACG & 0 & 0 & 164 & 11.11 & $2.5 \times 10^{-13 *}$ & $0.009^{* *}$ & $\begin{array}{c}0.001- \\
0.07\end{array}$ \\
\hline
\end{tabular}

* $\mathrm{p}$ value calculated using Fisher's exact test

** Odds Ratio calculated using Woolf's formula with Haldane's modification

@ Haplotypes were made using SHEsis online software $[19,20]$

$\$$ haplotypes showing significant differences are shown

Table 2: LMP2 and LMP7 SNPs and haplotypes in Type 1 diabetes patients compared with healthy controls.
$(\mathrm{Q})(\mathrm{p}<0.0098)$ and homozygous - CC $(\mathrm{QQ})(\mathrm{p}<0.03)$ were significantly increased in T1D. Allele $A(\mathrm{~K})(\mathrm{p}<0.0098)$ and genotype $A A(\mathrm{KK})$ were significantly reduced $(\mathrm{p}<0.03)$ in T1D patients compared to healthy controls. While the differences in allele frequencies remained significant even after the $\mathrm{p}$ value was corrected for multiple comparisons, the difference in genotype frequencies did not remain significant after correction.

In LMP7 Intron 6 the $G$ allele was significantly increased $(\mathrm{p}<0.01)$ and $T$ allele $(\mathrm{p}<0.01)$ and homozygous $T T(\mathrm{p}<0.03)$ were significantly reduced in T1D patients as compared to controls. The differences in allele frequencies remained significant even after the $p$ value was corrected for multiple comparisons; however, the difference in homozygous $T T$ genotype frequency between patients and controls did not remain significant after correction

Since $G$ allele of $L M P 2$ exon 3, $C$ alleles of $L M P 7$ exon 2 and $G$ allele of LMP7 intron 6 were significantly increased in T1D patients even after Bonferroni's correction; we wanted to study if there is a Linkage Disequilibrium (LD) between these alleles. For this purpose, haplotypes were constructed using online software SHEsis $[19,20]$ for 206 T1D and 738 healthy controls samples which were typed for all the three loci. Interestingly, as expected these SNPs were indeed in LD (Figure 2) and GCG ( $G$ allele of $L M P 2-C$ alleles of $L M P 7-G$ allele of $L M P 7$ intron 6) was the most frequent haplotype observed with a frequency of $62.37 \%$ in the patients compared to $39.56 \%$ in the controls and this difference was highly significant $\left(\mathrm{p}=5.9 \times 10^{-13}\right)$. Haplotype $A C T$ was observed with a frequency of $14.1 \%$ in patients compared to $5.42 \%$ in the controls and this difference was also significant $\left(\mathrm{p}=1.9 \times 10^{-8}\right)$. However, haplotypes

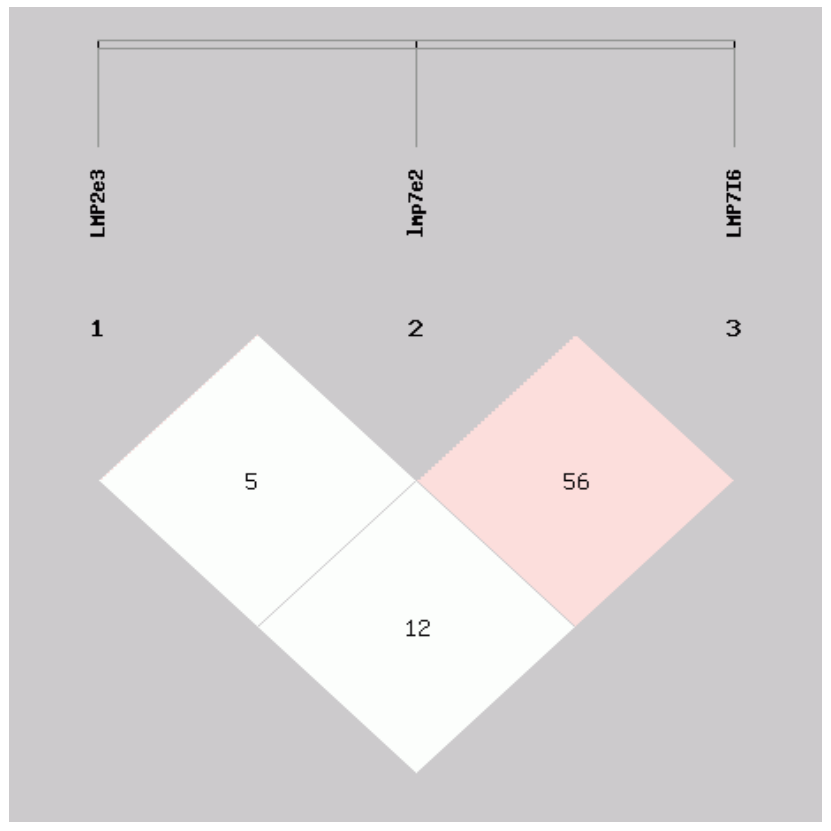

Linkage Disequilibrium tests

$\begin{array}{lcl}\text { D': } & \text { LMP7e2 } & \text { LMP7I6 } \\ \text { LMP2e3 } & 0.056 & 0.126 \\ \text { LMP7e2 } & - & 0.567\end{array}$

Figure 2: Linkage disequilibrium analysis for construction of haplotypes for LMP2 exon 3, LMP7 exon 2 and LMP7 Intron 6 using SHEsis online software $(19,20)$. 
Citation: Saida B, Dani P, Patnaik N, Agrawal B, Rajarathna T, et al. (2014) Haplotypes of Polymorphic Antigen Processing Genes for Low Molecular Mass Polypeptides (LMP2 and LMP7) are Strongly Associated with Type 1 Diabetes in North India. J Diabetes Metab 5: 451 doi:10.4172/21556156.1000451

Page 4 of 9

GCT and ACG were significantly reduced in T1D patients with a total absence of haplotype ACG. Differences in the haplotype frequencies were significant even after Bonferroni's correction.

Gender-wise distribution of genotype, allele and haplotype frequencies of $L M P 2$ and $L M P 7$ SNPs in gender matched T1D patients and controls

To check whether there is any gender bias in the LMP2 and $L M P 7$ alleles associated with T1D, 101 females and 134 male T1D patients' genotypes and haplotypes were compared with 199 healthy females and 552 healthy males respectively as shown in Tables 3 and 4 . The data showed that for $L M P 2$ codon 60 , allele $G(\mathrm{R})(\mathrm{p}<0.015)$ and genotype $G G(\mathrm{RR})(\mathrm{p}<0.016)$ were significantly increased and allele $A(\mathrm{H})$ was significantly reduced $(\mathrm{p}<0.015)$ in female patients compared with female controls (Table 3 ) and these differences were significant even after Bonferroni's correction. While the difference in allele frequencies of these SNPs was not statistically significant in male patients compared to male controls (Table 4), haplotype GCG was significantly increased in both female $(65.29 \%)$ and male $(60.83 \%)$ patients compared to female (42.31\%) and male (39.3\%) controls respectively. Male patients showed significant increase in frequency of haplotype $A C T$ as compared to male controls, however, this difference was not observed in female patients. Haplotypes GCT and ACG were significantly reduced in both male and female patients compared to their control counterparts.

\section{Association of $L M P 2$ and $L M P 7$ SNPs with age at onset}

We further analyzed the data to check if age at onset of the disease was associated with any particular SNPs of LMP2 and LMP7 (Table 5). Patients were divided in two groups, those who were 14 years or less than 14 years old at the time of onset (considering onset of adolescence at the age of 14 years) and those above 14 years old at the time of onset of T1D. These two groups were compared with all healthy controls. The data revealed a significant increase in the frequencies of $G(R)$ allele $(\mathrm{p}<0.029)$ and homozygous GG $(\mathrm{RR})$ genotype $(\mathrm{p}<0.03)$ for $L M P 2$ codon 60, allele C (Q) for LMP 7 codon $49(\mathrm{p}<0.045)$ and $G$ allele for LMP7 Intron $6(\mathrm{p}<0.007)$ and $G G$ genotype $(\mathrm{p}<0.016)$ in T1D patients with early age at onset as compared to controls. However, there were no significant differences in the frequencies of these SNPs in patients with more than 14 years age at onset and healthy controls.

Interestingly, while individual SNPs showed significant differences only in patients with early age at onset, haplotypes GCG and ACT were significantly increased in both early $\left(\mathrm{p}<4.5 \times 10^{-11}, \mathrm{p}<0.003\right.$ respectively) and late age at onset $\left(\mathrm{p}<2 \times 10^{-5}\right.$ and $\mathrm{p}<5.14 \times 10^{-8}$ respectively). Similarly, haplotypes GCT and ACG were significantly reduced in patients with both early and late age at onset (Table 5).

\section{Linkage Disequilibrium analysis of $L M P 2$ and $L M P 7$ SNPs with $H L A$ - class- $I I$ alleles $D R B 1{ }^{\star} 03: 01$ and $D R B 1{ }^{\star} 07: 01$}

$L M P 2$ and LMP7 are localized in the MHC class-II region on chromosome $6 \mathrm{p} 21$, and we and others have earlier reported a very strong association of $H L A-D R B 1^{\star} 03: 01$ and negative association of

\begin{tabular}{|c|c|c|c|c|c|c|c|}
\hline \multirow{2}{*}{$\begin{array}{l}\text { Genotype/allele } \\
\text { LMP2 exon3 }\end{array}$} & \multirow{2}{*}{$\begin{array}{c}\text { TID } \\
\mathrm{N}=97 \\
\text { No. }\end{array}$} & \multirow[b]{2}{*}{$\%$} & \multirow{2}{*}{$\begin{array}{c}\text { Controls } \\
\begin{array}{c}\mathrm{N}=199 \\
\text { No. }\end{array}\end{array}$} & \multirow[b]{2}{*}{$\%$} & \multicolumn{3}{|c|}{ Female T1D vs. female controls } \\
\hline & & & & & p value & Odds ratio & 95\% C.I. \\
\hline GG & 71 & 73.19 & 117 & 58.79 & 0.016 & 1.91 & $1.09-3.39$ \\
\hline$G A$ & 25 & 25.77 & 75 & 37.69 & 0.04 & 0.57 & $0.32-1.01$ \\
\hline$A A$ & 1 & 1.03 & 7 & 3.52 & $0.2^{*}$ & $0.4^{\star *}$ & $0.11-1.4$ \\
\hline G & 167 & 86.08 & 309 & 77.64 & 0.015 & 1.78 & $1.09-2.96$ \\
\hline$A$ & 27 & 13.92 & 89 & 22.36 & 0.015 & 0.56 & $0.34-0.91$ \\
\hline LMP7 exon 2 & $N=101$ & $\%$ & $\mathrm{~N}=196$ & $\%$ & & & \\
\hline CC & 79 & 78.22 & 132 & 67.35 & 0.05 & 1.74 & $0.96-3.2$ \\
\hline$A C$ & 20 & 19.8 & 53 & 27.04 & 0.17 & 0.66 & $0.35-1.2$ \\
\hline$A A$ & 2 & 1.98 & 11 & 5.61 & $0.12^{*}$ & $0.4^{* *}$ & $0.15-1.08$ \\
\hline$C$ & 178 & 88.11 & 317 & 80.87 & 0.02 & 1.75 & $1.05-3.01$ \\
\hline$A$ & 24 & 11.88 & 75 & 19.13 & 0.02 & 0.57 & $0.33-0.95$ \\
\hline LMP7 Intron 6 & $\mathrm{~N}=96$ & $\%$ & $\mathrm{~N}=196$ & $\%$ & & & \\
\hline GG & 40 & 41.66 & 57 & 29.08 & 0.03 & 1.74 & $1.01-2.99$ \\
\hline$G T$ & 40 & 41.66 & 95 & 48.47 & 0.27 & 0.75 & $0.45-1.28$ \\
\hline$T T$ & 16 & 16.66 & 44 & 22.45 & 0.25 & 0.69 & $0.34-1.34$ \\
\hline G & 120 & 62.5 & 209 & 53.31 & 0.03 & 1.45 & $1.01-2.11$ \\
\hline$T$ & 72 & 37.5 & 183 & 46.69 & 0.03 & 0.68 & $0.47-0.99$ \\
\hline \multicolumn{8}{|c|}{ Haplotypes LMP2 exon 3, LMP7 exon 2, LMP7 intron 6@s } \\
\hline & $2 \mathrm{~N}=170$ & $\%$ & $2 \mathrm{~N}=390$ & $\%$ & & & \\
\hline GCG & 111 & 65.29 & 165 & 42.31 & $7.5 \times 10^{-6 *}$ & 2.36 & $1.61-3.45$ \\
\hline$A C T$ & 21 & 12.35 & 34 & 8.72 & $0.24^{*}$ & 1.41 & $0.79-2.51$ \\
\hline GCT & 18 & 10.59 & 81 & 20.8 & $0.002^{*}$ & 0.43 & $0.25-0.74$ \\
\hline$A C G$ & 0 & 0 & 34 & 8.72 & $4.1 \times 10^{-5 *}$ & $0.03^{* *}$ & $0.004-0.22$ \\
\hline
\end{tabular}

* $p$ value calculated using Fisher's exact test

** Odds Ratio calculated using Woolf's formula with Haldane's modification

@ Haplotypes were made using SHEsis online software $[19,20]$

$\$$ haplotypes showing significant differences are shown

Table 3: LMP2 and LMP7 SNPs and haplotypes in female Type 1 diabetes patients compared with female healthy controls. 
Citation: Saida B, Dani P, Patnaik N, Agrawal B, Rajarathna T, et al. (2014) Haplotypes of Polymorphic Antigen Processing Genes for Low Molecular Mass Polypeptides (LMP2 and LMP7) are Strongly Associated with Type 1 Diabetes in North India. J Diabetes Metab 5: 451 doi:10.4172/21556156.1000451

Page 5 of 9

\begin{tabular}{|c|c|c|c|c|c|c|c|}
\hline \multirow{3}{*}{$\begin{array}{l}\text { Genotype/allele } \\
\text { LMP2 exon3 }\end{array}$} & \multirow{2}{*}{\multicolumn{2}{|c|}{$\begin{array}{c}\text { TID } \\
\mathrm{N}=131 \%\end{array}$}} & \multirow{2}{*}{\multicolumn{2}{|c|}{$\begin{array}{l}\text { Controls } \\
N=553 \%\end{array}$}} & \multicolumn{3}{|c|}{ Male T1D vs. male controls } \\
\hline & & & & & \multirow{2}{*}{$\frac{p}{\text { Values }}$} & \multirow{2}{*}{$\begin{array}{l}\text { Odds } \\
\text { ratio }\end{array}$} & \multirow[t]{2}{*}{$95 \% \mathrm{Cl}$} \\
\hline & & & & & & & \\
\hline GG & 95 & 72.52 & 363 & 65.64 & 0.13 & 1.38 & $0.89-2.17$ \\
\hline GA & 32 & 24.43 & 166 & 30.02 & 0.2 & 0.75 & $0.47-1.18$ \\
\hline AA & 4 & 3.05 & 24 & 4.34 & $0.35^{*}$ & $0.76^{* *}$ & $0.37-1.57$ \\
\hline G & 222 & 84.73 & 892 & 80.65 & 0.12 & 1.33 & $0.91-1.97$ \\
\hline A & 40 & 15.27 & 214 & 19.35 & 0.12 & 0.75 & $0.5-1.09$ \\
\hline LMP7 exon 2 & \multicolumn{2}{|c|}{$\mathrm{N}=125 \%$} & \multicolumn{2}{|c|}{$N=546 \%$} & & & \\
\hline $\mathrm{CC}$ & 94 & 75.2 & 384 & 70.33 & 0.27 & 1.28 & $0.81-2.06$ \\
\hline$A C$ & 28 & 22.4 & 138 & 25.27 & 0.5 & 0.85 & $0.52-1.38$ \\
\hline AA & 3 & 2.4 & 24 & 4.4 & $0.22^{*}$ & $0.61^{* *}$ & $0.27-1.36$ \\
\hline C & 216 & 86.4 & 906 & 82.97 & 0.18 & 1.3 & $0.87-1.99$ \\
\hline A & 34 & 13.36 & 186 & 17.03 & 0.18 & 0.76 & $0.5-1.15$ \\
\hline LMP7 Intron 6 & \multicolumn{2}{|c|}{$\mathrm{N}=134 \%$} & \multicolumn{2}{|c|}{$\mathrm{N}=542 \%$} & & & \\
\hline GG & 50 & 37.31 & 188 & 34.68 & 0.56 & 1.12 & $0.7-1.68$ \\
\hline GT & 66 & 49.25 & 237 & 43.73 & 0.25 & 1.25 & $0.83-1.85$ \\
\hline TT & 18 & 13.43 & 117 & 21.59 & 0.034 & 0.56 & $0.31-0.97$ \\
\hline G & 166 & 61.94 & 613 & 56.55 & 0.11 & 1.25 & $0.94-1.66$ \\
\hline $\mathrm{T}$ & 102 & 38.06 & 471 & 43.45 & 0.11 & 0.8 & $0.6-1.06$ \\
\hline \multicolumn{8}{|c|}{ Haplotypes LMP2 exon 3, LMP7 exon 2, LMP7 intron 6@\$ } \\
\hline & \multicolumn{2}{|c|}{$2 \mathrm{~N}=240 \%$} & \multicolumn{2}{|c|}{$2 \mathrm{~N}=1086 \%$} & & & \\
\hline GCG & 146 & 60.83 & 427 & 39.3 & $8.5 \times 10^{-9 *}$ & 2.31 & $1.73-3.08$ \\
\hline$A C T$ & 36 & 15 & 62 & 5.71 & $1.3 \times 10^{-6 *}$ & 2.84 & $1.83-4.39$ \\
\hline GCT & 26 & 10.8 & 306 & 28.17 & $8.1 \times 10^{-9 *}$ & 0.3 & $0.19-0.46$ \\
\hline$A C G$ & 0 & 0 & 106 & 9.76 & $3.1 \times 10^{-7 *}$ & $0.009^{\star *}$ & $0.001-0.07$ \\
\hline
\end{tabular}

* $p$ value calculated using Fisher's exact test

** Odds Ratio calculated using Woolf's formula with Haldane's modification

@Haplotypes were made using SHEsis online software [19,20]

$\$$ haplotypes showing significant differences are shown

Table 4: LMP2 and LMP7 SNPs and haplotypes in male Type 1 diabetes patients compared with male healthy controls.

$D R B 1^{*} 07: 01$ with T1D $[4,5,7]$. So, to check whether the association of $L M P 2$ and $L M P 7$ SNPs in the present study were due to theirs being in Linkage Disequilibrium (LD) with the predisposing MHC allele, we calculated the co-efficient of LD (D') and co-efficient of correlation (r) between predisposing and protective HLA alleles with $L M P 2-L M P 7$ haplotypes (Table 6). Haplotypes GCG and GCT were in weak linkage disequilibrium with predisposing $H L A-D R B 1^{\star} 03: 01$ in both patients $\left(D^{\prime}=0.2273, r=0.1385\right.$ and $D^{\prime}=0.5337, r=0.1297$ respectively $)$ and controls $\left(D^{\prime}=0.06337, r=0.1349\right.$ and $\left.D^{\prime}=0.07436, r=0.0911\right)$. However, haplotype ACT was in stronger $L D$ with protective $D R B 1^{\star} 07: 01$ allele $\left(D^{\prime}=0.1594\right.$, $\mathrm{r}=0.2134)$. While haplotype $G C G$ and $A C T$ were significantly increased, GCT was significantly reduced in the patients. Weak $\mathrm{LD}$ of both predisposing $G C G$ and protective $G C T$ haplotypes with predisposing $D R B 1^{\star} 03: 01$ and that of predisposing $A C T$ with protective $D R B 1^{\star} 07: 01$ suggests that the association of $L M P 2-L M P 7$ haplotypes are independent of their $H L A$ alleles and not due to theirs being in $L D$ with the predisposing $H L A$ alleles. Interestingly, when we studied simultaneous presence of the predisposing and protective $L M P 2-L M P 7$ haplotypes with predisposing and protective $H L A$ alleles (Table 7), all three haplotypes GCG, ACT and GCT along with $D R B 1^{\star} 03: 01$, were significantly increased in T1D patients compared to control. And GCG and GCT along with $D R B 1^{\star} 07: 01$ were significantly reduced in T1D compared to controls. These results indicate the dominant effect of the predisposing $H L A$ allele $D R B 1^{\star} 03: 01$ which was present in more than $70 \%$ of the patients compared to only $15.7 \%$ of controls and was thus associated with both predisposing and protective $L M P 2-L M P 7$ haplotypes suggesting the independent role of predisposing
LMP2-LMP7 haplotypes.

\section{Discussion}

We show here that the haplotypes of antigen processing genes $L M P 2$ and $L M P 7$ may have a role in the aberrant presentation of self-antigens in T1D. $L M P 2$ and $L M P 7$ act as peptide editors for the appropriate peptide to be presented on the MHC molecules since they generate peptides that would better bind to MHC class-I molecules [21], and polymorphism in these genes may be detrimental for the peptides being loaded on MHC class-I molecules. There are controversial reports with respect to functional role of $L M P 2$ exon $3 \mathrm{SNP}$ at codon 60 where a single nucleotide polymorphism results in an amino acid change from arginine $(\mathrm{R})$ to histidine $(\mathrm{H})(C G C$ to $C A C)$. While there was no difference in the mRNA expression of $L M P 2$ in the $\mathrm{R}$ and $\mathrm{H}$ alleles, their chymotrypsin-like and trypsin-like activities were observed to be more in RR subjects compared to heterozygous RH subjects [22]. However, Park et al. [23] did not find any effect of the codon $60 \mathrm{R} / \mathrm{H}$ polymorphism on either expression or catalytic activity of LMP2 in some cancer cell lines. Since the cancer cell lines themselves showed a lot of variability in protein expression of LMP2, it is possible that situation may be different in normal non-cancerous cells. LMP2 codon $60 \mathrm{R} / \mathrm{H}$ ( $G / A$ ) polymorphism seems to be conserved since this polymorphism is observed in different strains of mice [24] including non-obese diabetic (NOD) mice, the animal model for human Typel diabetes, who also have $\mathrm{R}$ allele at codon 60. Results of $L M P 2$ polymorphisms in T1D are variable in different populations. While we found $L M P 2 G G$ 
Citation: Saida B, Dani P, Patnaik N, Agrawal B, Rajarathna T, et al. (2014) Haplotypes of Polymorphic Antigen Processing Genes for Low Molecular Mass Polypeptides (LMP2 and LMP7) are Strongly Associated with Type 1 Diabetes in North India. J Diabetes Metab 5: 451 doi:10.4172/21556156.1000451

Page 6 of 9

\begin{tabular}{|c|c|c|c|c|c|c|c|c|c|}
\hline \multirow{2}{*}{$\begin{array}{l}\text { Genotype/allele } \\
\text { LMP2 exon3 }\end{array}$} & \multirow{2}{*}{$\begin{array}{c}\text { TID } \\
\text { Onset age } \leq 14 \\
\mathrm{~N}=99 \\
(\%)\end{array}$} & \multirow{2}{*}{$\begin{array}{l}\text { Control } \\
\begin{array}{c}\mathrm{N}=752 \\
(\%)\end{array}\end{array}$} & \multicolumn{3}{|c|}{$\begin{array}{c}\text { Age at onset } \leq 14 \\
\text { Vs. } \\
\text { Controls }\end{array}$} & \multirow{2}{*}{$\begin{array}{c}\text { TID } \\
\text { Onset age } \\
>14 \\
\mathrm{~N}=117 \\
(\%)\end{array}$} & \multicolumn{3}{|c|}{$\begin{array}{l}\text { Age at onset }>14 \\
\text { Vs. Controls }\end{array}$} \\
\hline & & & p Value & Odds ratio & $95 \% \mathrm{Cl}$ & & p Value & $\begin{array}{l}\text { Odds } \\
\text { ratio }\end{array}$ & $95 \% \mathrm{Cl}$ \\
\hline GG & $\begin{array}{c}74 \\
(74.75)\end{array}$ & $480(63.82)$ & 0.03 & 1.67 & $1.02-2.82$ & $\begin{array}{c}83 \\
(70.94)\end{array}$ & 0.13 & 1.38 & $0.89-2.19$ \\
\hline$G A$ & $\begin{array}{c}23 \\
(23.2)\end{array}$ & $241(32.05)$ & 0.07 & 0.64 & $0.37-1.06$ & $\begin{array}{c}31 \\
(26.49)\end{array}$ & 0.23 & 0.76 & $0.47-1.2$ \\
\hline$A A$ & $\begin{array}{c}2 \\
(2.02)\end{array}$ & $\begin{array}{c}31 \\
(4.12)\end{array}$ & $0.24^{*}$ & $0.58^{* *}$ & $0.23-1.48$ & $\begin{array}{c}3 \\
(2.56)\end{array}$ & $0.3^{*}$ & $0.7^{\star *}$ & $0.31-1.54$ \\
\hline$G$ & $\begin{array}{c}171 \\
(86.4)\end{array}$ & $1201(79.85)$ & 0.029 & 1.598 & $1.04-2.54$ & $\begin{array}{c}197 \\
(84.19)\end{array}$ & 0.12 & 1.34 & $0.92-2.0$ \\
\hline$A$ & $\begin{array}{c}27 \\
(13.6)\end{array}$ & $303(20.14)$ & 0.029 & 0.625 & $0.39-0.96$ & $\begin{array}{c}37 \\
(15.81)\end{array}$ & 0.12 & 0.74 & $0.49-1.08$ \\
\hline LMP7 exon 2 & $\mathrm{~N}=97$ & $N=742$ & & & & $N=115$ & & & \\
\hline$C C$ & $\begin{array}{c}75 \\
(77.32)\end{array}$ & $516(69.54)$ & 0.11 & 1.49 & $0.89-2.59$ & $\begin{array}{c}88 \\
(76.52)\end{array}$ & 0.12 & 1.43 & $0.89-2.35$ \\
\hline$A C$ & $\begin{array}{c}21 \\
(21.65)\end{array}$ & $191(25.74)$ & 0.38 & 0.79 & $0.45-1.35$ & $\begin{array}{c}24 \\
(20.87)\end{array}$ & 0.26 & 0.76 & $0.45-1.25$ \\
\hline$A A$ & $\begin{array}{c}1 \\
(1.03)\end{array}$ & $35(4.72)$ & $0.06^{*}$ & $0.31^{* *}$ & $0.09-0.99$ & $\begin{array}{c}3 \\
(2.61)\end{array}$ & $0.22^{*}$ & $0.62^{\star \star}$ & $0.28-1.36$ \\
\hline$C$ & $\begin{array}{c}171 \\
(88.14)\end{array}$ & $1223(82.41)$ & 0.045 & 1.58 & $0.99-2.62$ & $\begin{array}{c}200 \\
(86.96)\end{array}$ & 0.087 & 1.42 & $0.94-2.21$ \\
\hline$A$ & $\begin{array}{c}23 \\
(11.86)\end{array}$ & $261(17.58)$ & 0.045 & 0.63 & $0.38-1.0$ & $\begin{array}{c}30 \\
(13.04)\end{array}$ & 0.087 & 0.7 & $0.45-1.06$ \\
\hline LMP7 Intron 6 & $\mathrm{~N}=99$ & $N=738$ & & & & $N=118$ & & & \\
\hline$G G$ & $\begin{array}{c}45 \\
(45.45)\end{array}$ & $\begin{array}{c}245 \\
(33.2)\end{array}$ & 0.016 & 1.67 & $1.07-2.62$ & $\begin{array}{c}42 \\
(35.59)\end{array}$ & 0.61 & 1.11 & $0.72-1.69$ \\
\hline$G T$ & $\begin{array}{c}40 \\
(40.4)\end{array}$ & 332 (44.99) & 0.39 & 0.82 & $0.53-1.29$ & $\begin{array}{c}57 \\
(48.3)\end{array}$ & 0.5 & 1.14 & $0.76-1.72$ \\
\hline$T T$ & $\begin{array}{c}14 \\
(14.14)\end{array}$ & $161(21.81)$ & 0.08 & 0.59 & $0.3-1.08$ & $\begin{array}{c}19 \\
(16.1)\end{array}$ & 0.16 & 0.69 & $0.38-1.17$ \\
\hline$G$ & $\begin{array}{c}130 \\
(65.66)\end{array}$ & $\begin{array}{c}822 \\
(55.7)\end{array}$ & 0.007 & 1.52 & $1.1-2.11$ & $\begin{array}{c}141 \\
(59.75)\end{array}$ & 0.22 & 1.19 & $0.89-1.59$ \\
\hline$T$ & $\begin{array}{c}68 \\
(34.34)\end{array}$ & $\begin{array}{c}654 \\
(44.3)\end{array}$ & 0.007 & 0.66 & $0.47-0.9$ & $\begin{array}{c}94 \\
(40.25)\end{array}$ & 0.22 & 0.84 & $0.62-1.12$ \\
\hline \multicolumn{10}{|c|}{ Haplotypes LMP2 exon 3,LMP7 exon 2, LMP7 intron 6@s } \\
\hline & $2 \mathrm{~N}=174$ & $2 \mathrm{~N}=1476$ & p Value & Odds ratio & $95 \% \mathrm{Cl}$ & $\mathrm{N}=\mathbf{2 1 0}$ & p Value & Odds ratio & $95 \% \mathrm{Cl}$ \\
\hline GCG & $\begin{array}{l}119 \\
(68.4)\end{array}$ & $584(39.6)$ & $4.5 \times 10^{-11 *}$ & 3.05 & $2.16-4.29$ & $\begin{array}{c}122 \\
(58.0)\end{array}$ & $2 \times 10^{-5 *}$ & 1.89 & $1.41-2.54$ \\
\hline$A C T$ & $\begin{array}{l}20 \\
(11.5)\end{array}$ & $80(5.42)$ & $0.003^{*}$ & 2.14 & $1.28-3.6$ & $\begin{array}{c}34 \\
(16.2)\end{array}$ & $5.14 \times 10^{-8 *}$ & 3.15 & $2.05-4.86$ \\
\hline$G C T$ & $\begin{array}{l}16 \\
(9.2)\end{array}$ & $387(26.22)$ & $1.96 \times 10^{-12 *}$ & 0.32 & $0.23-0.44$ & $\begin{array}{l}25 \\
(12)\end{array}$ & $6.85 \times 10^{-7 *}$ & 0.35 & $0.23-0.54$ \\
\hline$A C G$ & $\begin{array}{l}0 \\
(0)\end{array}$ & $164(11.11)$ & $2.47 \times 10^{-13 *}$ & $0.02^{* \star}$ & $0.003-0.16$ & $\begin{array}{c}0 \\
(0)\end{array}$ & $1.32 \times 10^{-7 *}$ & $0.02^{\star *}$ & $0.002-0.14$ \\
\hline
\end{tabular}

* $p$ value calculated using Fisher's exact test

** Odds Ratio calculated using Woolf's formula with Haldane's modification

@Haplotypes were made using SHEsis online software $[19,20]$

$\$$ haplotypes showing significant differences are shown

Table 5: Association of LMP2 and LMP7 SNPs and haplotypes with age at onset in Type 1 diabetes patients compared with healthy controls

(RR) genotype and $G(\mathrm{R})$ allele to be significantly increased in the $\mathrm{T} 1$ $\mathrm{D}$ patients, Deng et al. and Ding et al. reported the homozygous RR to be protective from diabetes in Caucasian and Chinese Han populations respectively $[25,26]$. However, several other studies did not find $L M P 2$ $\mathrm{R} / \mathrm{H}$ polymorphism to be associated with T1D [27,30]. A meta analysis done to resolve this problem of variable results suggested that $L M P 2 \mathrm{RH}$ genotype seemed to be associated with T1D [31], the results opposite to ours where we observed RR genotype to be disease conferring and heterozygous RH to be reduced in the patients compared to controls. These differences could be due to different ethnicity of the individuals studied in the present report.
In $L M P 7$ exon 2 glutamine (Q-CAG) [5] to Lysine (K- $A A G)$ substitution in the codon 49 has been implicated in the transcription regulation of the gene. On IFN-gamma stimulation cell lines with homozygous KK $(A A)$ genotype showed lower expression and reduced transcript stability compared to cell lines with $L M P 7 \mathrm{QQ}(C C)$ genotypes and heterozygous $\mathrm{K} / \mathrm{Q}$ cell lines showed intermediate expression of $L M P 7$ [32], suggesting that the $\mathrm{K}$ allele may reduce the formation of immunoproteasome, and thus peptide processing followed by reduced peptide-HLA presentation [32]. In the present scenario, we observed the QQ $(C C)$ genotype to be significantly increased in patients which may be involved in higher expression of the immunoproteasome 
Citation: Saida B, Dani P, Patnaik N, Agrawal B, Rajarathna T, et al. (2014) Haplotypes of Polymorphic Antigen Processing Genes for Low Molecular Mass Polypeptides (LMP2 and LMP7) are Strongly Associated with Type 1 Diabetes in North India. J Diabetes Metab 5: 451 doi:10.4172/21556156.1000451

Page 7 of 9

\begin{tabular}{|c|c|c|c|c|c|c|c|}
\hline $\begin{array}{l}\text { Haplotypes for LMP2 exon3- } \\
\text { LMP7 exon2-LMP7 intron6- } \\
\text { DRB1*03:01 }\end{array}$ & $\begin{array}{l}\text { Number of } \\
\text { haplotypes } \\
\text { observed }\end{array}$ & $\begin{array}{c}\text { Observed } \\
\text { haplotype } \\
\text { frequency } P_{a b}\end{array}$ & $\begin{array}{c}\text { Expected } \\
\text { haplotype frequency } \\
\left(\mathrm{P}_{\mathrm{a}} \times \mathrm{P}_{\mathrm{b})}\right.\end{array}$ & $\begin{array}{c}D= \\
\left(P_{a b}-P_{a} \times P_{b}\right)\end{array}$ & $D^{\prime}=D / P_{a}\left(1-P_{b}\right)$ & $r^{2}=D^{2} / P_{a} \times P_{b}$ & $\mathbf{r}=\sqrt{ } \mathbf{r}^{2}$ \\
\hline \multicolumn{8}{|l|}{ For T1D patients $2 \mathrm{~N}=398$} \\
\hline GCG-DRB1*03:01 & 148 & 0.3718 & 0.2964 & 0.0754 & 0.2273 & 0.0192 & 0.1385 \\
\hline GCG-DRB1*07:01 & 21 & 0.0527 & 0.0474 & 0.0054 & 0.00932 & 0.00062 & 0.0248 \\
\hline$A C T-D R B 1 * 03: 01$ & 33 & 0.0829 & 0.0746 & 0.0083 & 0.0998 & 0.00093 & 0.0305 \\
\hline$A C T-D R B 1 * 07: 01$ & 14 & 0.0352 & 0.0119 & 0.0233 & 0.1594 & 0.0455 & 0.2134 \\
\hline GCT-DRB1*03:01 & 30 & 0.0754 & 0.0472 & 0.02818 & 0.5337 & 0.0168 & 0.1297 \\
\hline GCT-DRB1*07:01 & 3 & 0.00754 & 0.00754 & 0 & 0 & 0 & 0 \\
\hline \multicolumn{8}{|l|}{ For healthy controls $2 \mathrm{~N}=700$} \\
\hline GCG-DRB1*03:01 & 51 & 0.0728 & 0.04437 & 0.02843 & 0.06337 & 0.01822 & 0.1349 \\
\hline GCG-DRB1*07:01 & 61 & 0.0871 & 0.0838 & 0.00329 & 0.008 & 0.00013 & 0.0114 \\
\hline$A C T-D R B 1 * 03: 01$ & 9 & 0.01286 & 0.0117 & 0.00116 & 0.0098 & 0.00012 & 0.0107 \\
\hline$A C T-D R B 1 * 07: 01$ & 16 & 0.0229 & 0.0221 & 0.0008 & 0.0074 & 2.896E-05 & 0.00538 \\
\hline GCT-DRB1*03:01 & 18 & 0.0257 & 0.01467 & 0.01103 & 0.07436 & 0.00829 & 0.0911 \\
\hline GCT-DRB1*07:01 & 39 & 0.0557 & 0.0277 & 0.028 & 0.207 & 0.0284 & 0.1685 \\
\hline
\end{tabular}

$P_{a b}=$ Observed haplotype frequency counted directly and divided by $2 \mathrm{~N}$ and the resulting haplotype frequencies were used to calculate $D, P_{a}=$ haplotype frequency (hf) of $\mathrm{GCG}, \mathrm{ACT}$ or GCT, $\mathrm{P}_{\mathrm{b}}=$ gene frequency of $D R B 1^{*} 03: 01$. Haplotype frequency of $\left(P_{\mathrm{a}}\right) \mathrm{GCG}=0.628, A C T=0.158, G C T=0.1, g f\left(P_{b}\right)$ of $D R B 1^{*} 03: 01=0.472, D R B 1^{*} 07: 01=0.0754$ in T1D. In controls hf frequency of $G C G=0.493, A C T=0.13, G C T=0.163$, gf of $D R B 1{ }^{*} 03: 01=0.09$, DRB $1{ }^{\star} 07: 01=0.17$

Table 6: Linkage disequilibrium analysis for $L M P 2$ exon3-LMP7 exon2-LMP7 intron6 haplotypes with predisposing and protective $H L A$ alleles

\begin{tabular}{|c|c|c|c|c|c|c|c|}
\hline \multirow[t]{2}{*}{ LMP2-LMP7 haplotypes-HLA DRB1 } & \multicolumn{2}{|l|}{ T1D } & \multicolumn{2}{|c|}{ Controls } & \multirow[b]{2}{*}{$P$ value } & \multirow[b]{2}{*}{ Odds Ratio } & \multirow[b]{2}{*}{ 95\% C.I. } \\
\hline & $\begin{array}{c}\text { No. of haplotypes } \\
2 \mathrm{~N}=398\end{array}$ & $\%$ & $\begin{array}{c}\text { No. of haplotypes } \\
2 \mathrm{~N}=700\end{array}$ & $\%$ & & & \\
\hline GCG-DRB1*03:01 & 148 & 37.19 & 51 & 7.28 & $1.5 \times 10^{-42}$ & 9.37 & $6.48-13.63$ \\
\hline GCG-DRB1*07:01 & 21 & 5.28 & 61 & 8.71 & 0.03 & 0.584 & 0.33-0.99 \\
\hline$A C T-D R B 1 * 03: 01$ & 33 & 8.29 & 9 & 1.28 & $5.9 \times 10^{-9}$ & 6.94 & $3.2-16.65$ \\
\hline$A C T-D R B 1^{*} 07: 01$ & 14 & 3.52 & 16 & 2.28 & 0.229 & 1.56 & $0.69-3.44$ \\
\hline GCT-DRB1*03:01 & 30 & 7.53 & 18 & 2.57 & 0.0001 & 3.08 & $1.64-5.96$ \\
\hline GCT-DRB1*07:01 & 3 & 0.75 & 39 & 5.57 & $0.00002^{*}$ & $0.148^{* *}$ & $0.07-0.32$ \\
\hline
\end{tabular}

${ }^{*} p$ value calculated using Fisher's exact test

${ }^{* *}$ Odds Ratio calculated using Woolf's formula with Haldane's modification

Table 7: Simultaneous presence of predisposing and protective LMP2-LMP7 haplotypes with predisposing and protective HLA alleles.

and may have a role in presentation of self antigens in T1D since upregulation of $L M P 2$ and $L M P 7$ can result in marked improvement of antigen presentation [33]. This may greatly enhance the efficiency of intracellular $\mathrm{T}$ cell epitope production, establishing the cytotoxic $\mathrm{T}$ cell repertoire and shaping their cytotoxic immune responses [34-36]. While there is dearth of studies on LMP7 exon $2 \mathrm{Q} / \mathrm{K}$ polymorphism in T1D, QQ homozygosity has been shown to be associated with another autoimmune disorder, juvenile rheumatoid arthritis (JRA) [37]. LMP7 exon $249 \mathrm{Q}$ allele is the most frequent allele in Mexicans [38], Japanese [39], Brazilian Guarani population [39] and the north Indians in the present study and $49 \mathrm{~K}$ allele has been shown to have lower frequency in most of the studies except in Caucasians from USA [11]. However, in the study by Casp et al. [11], there seems to be an error in either interpretation or typographical error for $C(\mathrm{Q})$ and the $A(\mathrm{~K})$ alleles since the frequency of $\mathrm{Q}$ allele in a random population from USA has been reported to be $88.1 \%$ in another study [40] compared to $88.1 \%$ for $A(\mathrm{~K})$ allele in the study by Casp et al. [11].

Our results are not in concordance with the earlier studies on $L M P 7$ intron 6 where homozygous $T T$ at $G / T$ at 37360 site was increased and $G G$ was reduced in T1D $[25,31,41]$, however, our results showed a significant decrease in the frequency of $T T$ genotype and $T$ allele and increase in $G$ allele frequency in T1D from North India. The reason for non-concordance with earlier published reports could be due to different ethnicity of the subjects studied in the present report and larger numbers patients and controls studied compared to most of the earlier reports.

LMP2 and LMP7 are both immunoproteosomes involved in antigen processing and act in concert with each other and thus may have integrated and synergistic roles in generation of MHC class-I fitting peptides. So, we checked for the first time, whether there were any significant differences in the frequencies of haplotypes of $L M P 2$ exon $3 A / G, L M P 7$ exon $2 A / C$ and $L M P 7$ Intron $6 \mathrm{G} / T$ in T1D compared to controls. Comparison of haplotypes showed that haplotypes GCG and ACT were significantly increased in the patients and GCT and $A C G$ were significantly reduced in them, irrespective of gender of the patients or age at onset of diabetes. We further checked whether this effect could be due to $L M P 2$ and $L M P 7$ being in LD with predisposing $M H C$ class-II allele $D R B 1^{\star} 03: 01$ [4,5]. Our results showed that $L M P$ haplotype GCG was in weak linkage disequilibrium with predisposing $H L A-D R B 1^{*} 03: 01$ and not with protective $H L A$ $D R B 1^{*} 07: 01$, both in patients and controls, however, $37.19 \%$ of the T1D patients had GCG-DRB1*03:01 compared to $7.28 \%$ of the control and this was a highly significant difference with and Odds Ratio of 9.37. Similarly, other $L M P$ haplotypes $A C T$ and GCT along with $D R B 1^{*} 03: 01$ were significantly increased in the patients and the same haplotypes along with $D R B 1^{\star} 07: 01$ were significantly reduced in the patients. $L M P$ haplotype GCT by itself was significantly reduced and haplotype $G C G$ was significantly increased in the patients, however, significant increase in the simultaneous presence of both these haplotypes along with predisposing $H L A D R B 1^{\star} 03: 01$ and significant decrease along 
Citation: Saida B, Dani P, Patnaik N, Agrawal B, Rajarathna T, et al. (2014) Haplotypes of Polymorphic Antigen Processing Genes for Low Molecular Mass Polypeptides (LMP2 and LMP7) are Strongly Associated with Type 1 Diabetes in North India. J Diabetes Metab 5: 451 doi:10.4172/21556156.1000451

Page 8 of 9

with HLA $D R B 1^{\star} 07: 01$ clearly shows that while the predisposing $M H C$ alleles have the dominant effect, association of LMP2/LMP7 haplotypes is independent of the HLA alleles.

In conclusion, our results demonstrate that the significant increase in frequencies of haplotypes GCG and $A C T$ and decrease in the frequency of $G C T$ and $A C G$ haplotypes is independent of gender, age at onset and the predisposing HLA alleles and may have a significant role in manifestation of T1D through higher presentation of self antigens, activation of early $\mathrm{T}$ cell responses and differentiating them into effector cells through polarizing cytokines $[33,36]$. While association with $M H C$ class-II allele $D R B 1^{*} 03: 01$ [7] may be involved in generating Th1 type responses, predisposing $M H C$ class-I alleles [5] and LMP2$L M P 7$ haplotypes may be involved in generating self reactive cytotoxic T cells. Since all three SNPs of $L M P 2-L M P 7$ are very closely linked and are inherited en-bloc as a haplotype and the two proteosomes may be functioning in an integrated manner, it may be more relevant to study the haplotypes rather than individual SNPs in future studies.

\section{Acknowledgements}

Authors are thankful to study participants and Dr. Ravinder Goswami, All India Institute of Medical Sciences for diagnosis of the patients and for providing blood samples without which the study would not have been possible. This work was supported by grant from Department of Science \& Technology, New Delhi, India grant No. SP/SO/B54/98 and core grant from National Institute of Immunology, New Delhi, India.

\section{References}

1. Pociot F, McDermott MF (2002) Genetics of type 1 diabetes mellitus. Genes Immun 3: 235-249.

2. Todd JA (1995) Genetic analysis of type 1 diabetes using whole genome approaches. Proc Natl Acad Sci U S A 92: 8560-8565.

3. Ramachandran A, Snehalatha C, Krishnaswamy CV (1996) Incidence of IDDM in children in urban population in southern India. Madras IDDM Registry Group Madras, South India. Diabetes Res Clin Pract 34: 79-82.

4. Israni N, Goswami R, Kumar A, Rani R (2009) Interaction of vitamin D recepto with HLA DRB1 0301 in type 1 diabetes patients from North India. PLoS One 4: e8023.

5. Kumar R, Goswami R, Agarwal S, Israni N, Singh SK, et al. (2007) Association and interaction of the TNF-alpha gene with other pro- and anti-inflammatory cytokine genes and HLA genes in patients with type 1 diabetes from North India. Tissue Antigens 69: 557-567.

6. Bennett ST, Todd JA (1996) Human type 1 diabetes and the insulin gene: principles of mapping polygenes. Annu Rev Genet 30: 343-370.

7. Rani R, Sood A, Goswami R (2004) Molecular basis of predisposition to develop type 1 diabetes mellitus in North Indians. Tissue Antigens 64: 145-155.

8. Spies T, Bresnahan M, Bahram S, Arnold D, Blanck G, et al. (1990) A gene in the human major histocompatibility complex class II region controlling the class I antigen presentation pathway. Nature 348: 744-747.

9. Van Kaer L (2008) Pillars article: antigen presentation: discovery of the peptide TAP. J Immunol 180: 2723-2724.

10. Cresswell P, Ackerman AL, Giodini A, Peaper DR, Wearsch PA (2005) Mechanisms of $\mathrm{MHC}$ class I-restricted antigen processing and crosspresentation. Immunol Rev 207: 145-157.

11. Casp CB, She JX, McCormack WT (2003) Genes of the LMP/TAP cluster are associated with the human autoimmune disease vitiligo. Genes Immun 4: 492 499

12. Ortiz-Navarrete V, Seelig A, Gernold M, Frentzel S, Kloetzel PM, et al. (1991) Subunit of the '20S' proteasome (multicatalytic proteinase) encoded by the major histocompatibility complex. Nature 353: 662-664.

13. Hayashi T, Faustman DL (2001) Selected contribution: Association of genderrelated LMP2 inactivation with autoimmune pathogenesis. J Appl Physiol (1985) 91: 2804-2815.

14. Goswami R, Marwaha RK, Goswami D, Gupta N, Ray D, et al. (2006) Prevalence of thyroid autoimmunity in sporadic idiopathic hypoparathyroidism in comparison to type 1 diabetes and premature ovarian failure. $\mathrm{J}$ Clin Endocrinol Metab 91: 4256-4259.

15. Singh A, Sharma P, Kar HK, Sharma VK, Tembhre MK, et al. (2012) HLA alleles and amino-acid signatures of the peptide-binding pockets of HLA molecules in vitiligo. J Invest Dermatol 132: 124-134

16. Woolf B (1955) On estimating the relation between blood group and disease. Ann Hum Genet 19: 251-253.

17. Haldane JB (1956) The estimation and significance of the logarithm of a ratio of frequencies. Ann Hum Genet 20: 309-311.

18. Rani R, Fernandez-Viña MA, Stastny P (1998) Associations between HLA class II alleles in a North Indian population. Tissue Antigens 52: 37-43.

19. Shi YY, He L (2005) SHEsis, a powerful software platform for analyses of linkage disequilibrium, haplotype construction, and genetic association at polymorphism loci. Cell Res 15: 97-98.

20. Li Z, Zhang Z, He Z, Tang W, Li T, et al. (2009) A partition-ligation-combinationsubdivision $E M$ algorithm for haplotype inference with multiallelic markers: update of the SHEsis (http://analysis.bio-X.cn). Cell Res 19: 519-523.

21. Miller Z, Ao L, Kim KB, Lee W (2013) Inhibitors of the immunoproteasome: current status and future directions. Curr Pharm Des 19: 4140-4151.

22. Mishto M, Bellavista E, Santoro A, Stolzing A, Ligorio C, et al. (2006) Immunoproteasome and LMP2 polymorphism in aged and Alzheimer's disease brains. Neurobiol Aging 27: 54-66.

23. Park JE, Ao L, Miller Z, Kim K, Wu Y, et al. (2013) PSMB9 codon 60 polymorphisms have no impact on the activity of the immunoproteasome catalytic subunit B1i expressed in multiple types of solid cancer. PLoS One 8: e73732

24. Zhou P, Cao H, Smart M, David C (1993) Molecular basis of genetic polymorphism in major histocompatibility complex-linked proteasome gene (Lmp-2). Proc Natl Acad Sci U S A 90: 2681-2684.

25. Deng GY, Muir A, Maclaren NK, She JX (1995) Association of LMP2 and LMP7 genes within the major histocompatibility complex with insulin-dependent diabetes mellitus: population and family studies. Am J Hum Genet 56: 528-534

26. Ding HL, Cheng H, Fu ZZ, Deng QL, Yan, Tang Yan L, et al. (2000) The relationship of Imp2 and DR3 genes with susceptibility to type I diabetes mellitus in south China Han population. World J Gastroenterol 6: 111-114.

27. van Endert PM, Liblau RS, Patel SD, Fugger L, Lopez T, et al. (1994) Major histocompatibility complex-encoded antigen processing gene polymorphism in IDDM. Diabetes 43: 110-117.

28. Undlien DE, Akselsen HE, Joner G, Dahl-Jørgensen $K$, Søvik O, et al (1997) No independent associations of LMP2 and LMP7 polymorphisms with susceptibility to develop IDDM. Diabetes 46: 307-312.

29. Kawaguchi Y, Ikegami H, Fukuda M, Takekawa K, Fujioka Y, et al. (1994) Absence of association of TAP and LMP genes with type 1 (insulin-dependent) diabetes mellitus. Life Sci 54: 2049-2053.

30. Chauffert M, Cissé A, Chevenne D, You JF, Michel S, et al. (1997) Susceptibility to type 1 diabetes in the Senegalese population is linked to HLA-DQ and not TAP and LMP genes. Diabetes Care 20: 1299-1303.

31. Sia C, Weinem M (2005) Genetic susceptibility to type 1 diabetes in the intracellular pathway of antigen processing - a subject review and cross-study comparison. Rev Diabet Stud 2: 40-52.

32. Fellerhoff B, Gu S, Laumbacher B, Nerlich AG, Weiss EH, et al. (2011) The LMP7-K allele of the immunoproteasome exhibits reduced transcript stability and predicts high risk of colon cancer. Cancer Res 71: 7145-7154.

33. Schwarz K, van Den Broek M, Kostka S, Kraft R, Soza A, et al. (2000) Overexpression of the proteasome subunits LMP2, LMP7, and MECL-1, but not PA28 alpha/beta, enhances the presentation of an immunodominant lymphocytic choriomeningitis virus T cell epitope. J Immunol 165: 768-778.

34. Basler M, Youhnovski N, Van Den Broek M, Przybylski M, Groettrup M (2004) Immunoproteasomes down-regulate presentation of a subdominant $\mathrm{T}$ cell epitope from lymphocytic choriomeningitis virus. J Immunol 173: 3925-3934.

35. Chen W, Norbury CC, Cho Y, Yewdell JW, Bennink JR (2001) Immunoproteasomes shape immunodominance hierarchies of antiviral CD8(+ $T$ cells at the levels of $T$ cell repertoire and presentation of viral antigens. J Exp Med 193: 1319-1326. 
Citation: Saida B, Dani P, Patnaik N, Agrawal B, Rajarathna T, et al. (2014) Haplotypes of Polymorphic Antigen Processing Genes for Low Molecular Mass Polypeptides (LMP2 and LMP7) are Strongly Associated with Type 1 Diabetes in North India. J Diabetes Metab 5: 451 doi:10.4172/21556156.1000451

36. Muchamuel T, Basler M, Aujay MA, Suzuki E, Kalim KW, et al. (2009)A selective inhibitor of the immunoproteasome subunit LMP7 blocks cytokine production and attenuates progression of experimental arthritis. Nat Med 15: 781-787.

37. Prahalad S, Kingsbury DJ, Griffin TA, Cooper BL, Glass DN, et al. (2001) Polymorphism in the MHC-encoded LMP7 gene: association with JRA without functional significance for immunoproteasome assembly. J Rheumatol 28: 2320-2325.

38. Vargas-Alarcón G, Gamboa R, Vergara Y, Rodriguez-Zepeda JM, de la Peña A, et al. (2002) LMP2 and LMP7 gene polymorphism in Mexican populations: Mestizos and Amerindians. Genes Immun 3: 373-377.

39. Faucz FR, Probst CM, Petzl-Erler ML (2000) Polymorphism of LMP2, TAP1, LMP7 and TAP2 in Brazilian Amerindians and Caucasoids: implications for the evolution of allelic and haplotypic diversity. Eur J Immunogenet 27: 5-16.
40. Lim JK, Hunter J, Fernandez-Vina M, Mann DL (1999) Characterization of LMP polymorphism in homozygous typing cells and a random population. Hum Immunol 60: 145-151.

41. Ding H, Cheng H, Fu Z, Yan L, Yang G (2001) Relationship of large multifunctional proteasome 7 gene polymorphism with susceptibility to type 1 diabetes mellitus and DR3 gene. Chin Med J (Engl) 114: 1263-1266.

42. Deshpande A, Wheeler CM, Hunt WC, Peyton CL, White PS, et al. (2008) Variation in HLA class I antigen-processing genes and susceptibility to human papillomavirus type 16-associated cervical cancer. J Infect Dis 197: 371-381. 